Proceedings of the International Congress on Advances in Applied Physics and Materials Science, Antalya 2011

\title{
Structural Characterization of Some Table Salt Samples by XRD, ICP, FTIR and XRF Techniques
}

\author{
Ş. YALÇIN ${ }^{a}$ AND İ.H. MUtLU ${ }^{b}$ \\ ${ }^{a}$ Central Laboratory, Harran University, 63300, Şanlıurfa, Turkey \\ ${ }^{b}$ Faculty of Arts and Science, Department of Physics, Harran University, 63300, Şanlıurfa, Turkey \\ In this study, we have investigated structure and impurities of six different salts which have a great \\ importance in our everyday life, namely source salt, Himalayan salt, rock salt, sea salt, lake salt and reduced \\ sodium salt (minsalt) by means of different analytical methods, namely X-ray powder diffraction, scanning \\ electron microscope-energy dispersive X-ray spectroscopy, inductive coupling plasma optic emission spectroscopy, \\ $\mathrm{X}$-ray fluorescence spectrometer and the Fourier transform infrared spectroscopy. With the light of obtained \\ results, suitability and performance of the different analytical methods were discussed in some details.
}

PACS: 61.05.cp

\section{Introduction}

Salt is one of the oldest minerals discovered and used by human. It has been used to sweeten and hide of nutrition from old. Depending on the formation, salts may be named as lake, sea, rock, source, Himalayan salt. Lake salt is obtained from old sea areas or from salty water passing over rock salts and forming lakes in appropriate areas. Sea salt is obtained from sea. In this study, sea salt was obtained by evaporation of sea water collected from Aegean region. Rock salt is found as solid under soil. This salt is formed by evaporation of inland sea water in hot climate condition with time. Source salt is obtained from river, well and sources [1].

In a study, mineralogical investigation of samples taken to determine of heavy metal quantities were conducted using X-ray powder diffractometer (XRD) system and geochemical analyses of samples were determined using atomic absorption spectrometer with graphite oven. Using the methods mentioned above, the concentrations of $\mathrm{Cu}, \mathrm{Al}, \mathrm{Pb}, \mathrm{As}, \mathrm{Hg}, \mathrm{Fe}, \mathrm{Cr}$, Se, Cd, Co, Mn, Ni were compared. X-ray diffraction analysis showed that the samples mainly include halite $(\mathrm{NaCl})$, whereas, according to X-ray powder diffraction analysis results, the samples also include $\mathrm{CaCl}_{2}$ at much less amount [2]. Lake salts may also include some heavy metals, such as Fe 1.27 - $1.55 \mathrm{mg} / \mathrm{l}, \mathrm{Pb} 0.33-0.67 \mathrm{mg} / \mathrm{l}, \mathrm{Mn} 0.15-0.17 \mathrm{mg} / \mathrm{l}$, $\mathrm{Cu} 0.11-0.20 \mathrm{mg} / \mathrm{l}, \mathrm{Zn} 0.02-0.08 \mathrm{mg} / \mathrm{l}$ [3].

There are various methods used for structural analyses. Hannaker et al. [4] compared inducting coupling plasma-optic emission spectroscopy and X-ray fluorescence (ICP-OES and XRF) methods in the analyses of some geologic samples. In wide concentration interview, they used a lot of elements. In wide concentration examination, they used many elements and stated that analysis results were similar to the results obtained by ICPOES and XRF. Somogyi et al. [5] performed Mn, Zn, Fe and $\mathrm{Sr}$ analyses in sedimentary rock samples in marsh using XRF and ICP. XRF and ICP gave similar results in Mn, Zn and Fe analyses, but ICP gave lower standard deviations in Sr analyses. Marina and Lopez [6] compared with XRF and ICP methods of phosphorus amounts in ceramic raw material. They reported that there are obtained quotable results by both methods and sensitivity of XRF is high due to the fact that XRF account for smaller error in sample preparation. In this study, by using XRD, SEM/EDX, ICP, XRF and the Fourier transform infrared (FTIR) structure of this salt samples were illuminated.

\section{Method}

In this study, the characterization of the salts is carried out with a number of experimental approaches in order to investigate all the relevant features. XRD patterns of the salts were obtained by a Rigaku model powder X-ray diffractometer with $\mathrm{Cu} K$ alpha radiation. Also, by using ZEIS EVO 50 scanning electron microscope, elemental analyses of these salts were performed. By using Perkin Elmer Optima 5300 DV optic emission spectrometer (ICP), chemical elements in salts were determined. The salts were subjected to wavelength distribution X-ray fluorescence spectrometer (WD/XRF) to analyze the chemical composition or elements present in the sample. The salts were investigated for their vibration spectra with infrared spectroscopy using Perkin Elmer 1800 model instrument from $450 \mathrm{~cm}^{-1}$ to $4400 \mathrm{~cm}^{-1}$ by using $\mathrm{KBr}$ tablet.

\section{Results and discussion}

In order to understate the nature of the salts, XRD, SEM (EDX), ICP, XRF and FTIR studies were performed. The presences of above minerals were further tested by XRD studies (Fig. 1). XRD is used to determine the mineralogical composition of the raw material components as well as qualitative and quantitative phase analysis of multiphase mixtures. XRD analyses were used 
to determine the structure of salts. Halite potassian was observed in all salt samples (Table I).

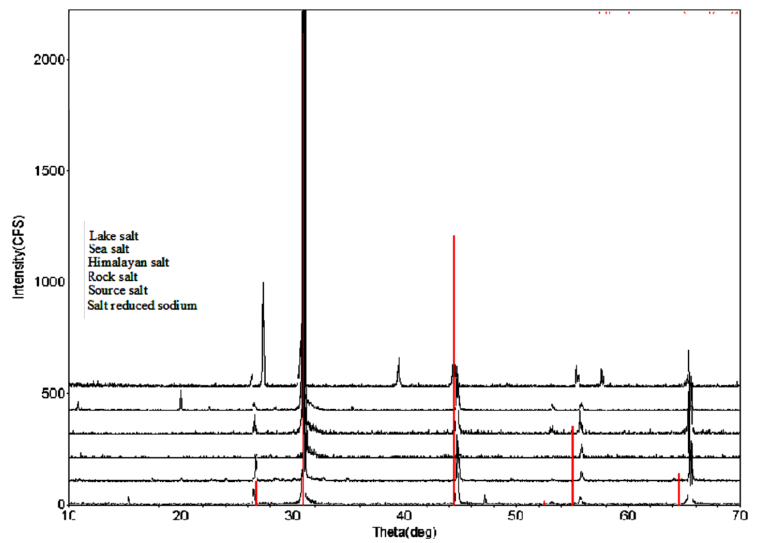

Fig. 1. XRD patterns of table salts.

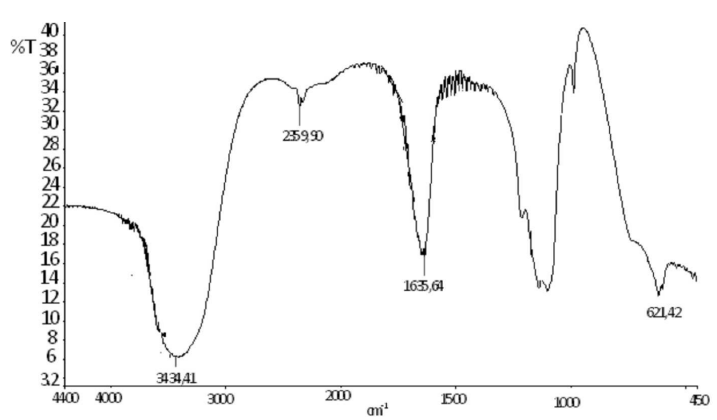

Fig. 2. FTIR spectrum of lake salt.

Secondly, structure of these salts was investigated by $\mathrm{SEM} / \mathrm{EDX}$. This is given in Table II. ICP results are shown in Table III. As known from literature, in structure of the salts, $\mathrm{Na}$ and $\mathrm{Cl}$ are found. In our study, $\mathrm{Na}$ has been found for all salts.

XRF results of samples are shown in Table IV.

FTIR studies of the salts help in the identification of minerals present in the salts. The coupled vibrations are appreciable due to availability of various constituents. In

Fig. 2, FTIR spectrum of lake salt is shown.

In all samples, there are 3410, 3452, 3420, 3446, 3434, 3468 and 1635 peaks. This peaks come from water in structure of sample. We estimated that 2360 value comes from carbon dioxide in air and it has been shown in all samples (Table V).

$\mathrm{X}$-ray diffraction studies show the presence of halite potassian. XRF and ICP analyses clearly indicate that the higher rate of sodium (for ICP) and chlorine (for $\mathrm{XRF}$ ) than other elements is predicted. Results have complemented feature to each other.

XRD results.

TABLE I

\begin{tabular}{l|c|c}
\hline \hline \multicolumn{1}{c|}{ Salts } & Matter determined & PDF number \\
\hline source & halite potassian, syn & $00-026-0918$ \\
Himalayan & halite potasian, syn & $01-075-0305$ \\
minsalt & halite potassian, & $01-075-0304$, \\
& iron potassium fluoride & $01-076-2399$ \\
rock & halite potasian, syn & $01-075-0305$ \\
sea & halite potasian, syn & $01-075-0305$ \\
lake & halite syn & $01-089-3615$
\end{tabular}

$\mathrm{SEM} / \mathrm{EDX}$ analysis results

TABLE II

\begin{tabular}{c|c|c|c|c|c|c}
\hline \hline \multirow{2}{*}{ Elem. } & \multicolumn{6}{|c}{ C norm. [wt.\%] } \\
\cline { 2 - 7 } & lake & sea & Himal. & rock & source & minsalt \\
\hline $\mathrm{Cl}$ & 48.25 & 38.84 & 45.60 & 20.10 & 53.09 & 48.09 \\
$\mathrm{Mg}$ & 18.24 & 43.34 & & 16.09 & & 5.13 \\
$\mathrm{~S}$ & 17.50 & 4.12 & & 6.55 & 0.02 & \\
$\mathrm{~K}$ & 6.04 & 3.42 & & 2.61 & & 44.56 \\
$\mathrm{Ca}$ & 4.37 & & 0.29 & 3.38 & 0.58 & 0.83 \\
$\mathrm{Na}$ & 4.08 & 4.55 & 53.64 & 23.71 & 46.31 & 1.40 \\
$\mathrm{Al}$ & 0.71 & 5.73 & 0.47 & 9.13 & & \\
$\mathrm{Si}$ & 0.49 & & & & & \\
$\mathrm{Ni}$ & 0.31 & & & & & \\
$\mathrm{Cu}$ & & & & 18.43 & &
\end{tabular}

TABLE III

ICP measurement results $[\mathrm{mg} / \mathrm{kg}]$.

\begin{tabular}{l|c|c|c|c|c|c|c|c}
\hline \hline \multicolumn{1}{c|}{ Salts } & $\mathrm{Al}$ & $\mathrm{Ca}$ & $\mathrm{Cu}$ & $\mathrm{Fe}$ & $\mathrm{K}$ & $\mathrm{Mg}$ & $\mathrm{Na}$ & $\mathrm{P}$ \\
& 396.153 & 317.933 & 327.393 & 238.204 & 766.490 & 285.213 & 589.592 & 214.914 \\
\hline source & $<5$ & 2123.5 & $<5$ & 17.78 & 265.15 & 144.85 & 374150 & 2.275 \\
Himalaya & $<5$ & 178.1 & $<5$ & 5.59 & 552.3 & $<5$ & 378700 & $<5$ \\
minsalt & $<5$ & 92.36 & $<5$ & 5.818 & 244800 & 1434 & 99455 & $<5$ \\
rock & $<5$ & 1044.75 & $<5$ & 11.595 & 283.95 & 89.56 & 368900 & 2.197 \\
sea & 5.629 & 7944 & $<5$ & 13.465 & 9278.5 & 10395 & 325900 & 3.421 \\
lake & 3.213 & 1827.5 & $<5$ & 8.469 & 4048 & 3379 & 339000 & $<5$
\end{tabular}


$\mathrm{XRF}$ results [\%].

TABLE IV

\begin{tabular}{l|c|c|c|c|c|c|c|c|c|c|c}
\hline \hline \multicolumn{1}{c|}{ Salts } & $\mathrm{Cl}$ & $\mathrm{Na}_{2} \mathrm{O}$ & $\mathrm{CaO}$ & $\mathrm{SO}_{3}$ & $\mathrm{~K}_{2} \mathrm{O}$ & $\mathrm{MgO}$ & $\mathrm{SiO}_{2}$ & $\mathrm{Al}_{2} \mathrm{O}_{3}$ & $\mathrm{Fe}_{2} \mathrm{O}_{3}$ & $\mathrm{Br}$ & $\mathrm{SrO}$ \\
\hline source & 46.07 & 32.69 & 1.24 & 1.39 & 0.079 & 0.416 & 0.0937 & 0.042 & 0.0114 & - & 0.0088 \\
Himalayan & 40.76 & 35.52 & 0.050 & 0.161 & 0.053 & 0.649 & 0.0594 & 0.025 & 0.0176 & - & - \\
minsalt & 30.19 & 7.59 & 0.053 & 0.023 & 26.84 & 0.873 & 0.0218 & 0.007 & - & 0.0158 & - \\
rock & 42.24 & 29.29 & 1.253 & 1.112 & 0.411 & 0.364 & 0.1951 & 0.115 & 0.0314 & 0.0088 & 0.0038 \\
sea & 3.096 & 1.79 & 0.218 & 0.547 & 0.170 & 0.626 & 0.0093 & 0.005 & 0.0022 & 0.0031 & 0.0019 \\
lake & 37.92 & 20.43 & 0.769 & 2.323 & 1.034 & 5.129 & 0.1474 & 0.084 & 0.0180 & 0.0156 & 0.0078
\end{tabular}

FTIR spectrum bands $\left[\mathrm{cm}^{-1}\right]$.

TABLE V

\begin{tabular}{c|c|c|c|c|c}
\hline \hline Sea salt & Source salt & Rock salt & Lake salt & Himalayan salt & Minsalt \\
\hline 3851.97 & & & & & \\
3410.03 & 3420.68 & 3446.96 & 3434.61 & 3468.68 & 3452 \\
2360.16 & 2361.66 & 2360.30 & 2359.90 & 2360.26 & 2360.52 \\
1635.73 & 1635.91 & 1635.96 & 1635.64 & 1635.96 & 1636.08 \\
1520.90 & & & & & \\
& & & & & 1488.55 \\
1436.78 & & & & & 1423.62 \\
1124.58 & 1118.00 & & 1102.65 & & 1119.68 \\
605.86 & 603.62 & 668.10 & 604.17 & 668.11 & 594.91
\end{tabular}

\section{Acknowledgments}

Authors thank the HÜBAK for financial support, Harran University Central Lab. (HÜMEL) for XRD and ICP measurement, Harran University, Faculty of Arts and Science, Department of Chemistry for FTIR measurement, Erciyes University (TEKMER) for XRF measurement.

\section{References}

[1] Z. Ergin, TMMOB Mineral Engineering Room, Mining J. 27, 9 (1988).
[2] R. Saral, M.Sc. Thesis, Gebze Institute of Technology, Kocaeli (Turkey) 2000.

[3] A.M. Kılıç, in: V. Natl. Environment Eng. Congress, Ministry of Environment, Ankara 2003, p. 584.

[4] P. Hannaker, M. Haukka, S.K. Sen, Chem. Geol. 42, 319 (1984).

[5] A. Somogyi, M. Braun, J. Posta, Spectrochim. Acta Part B 52, 2011 (1997).

[6] M.A. Marina, M.C. Blanco Lopez, Analyt. Chim. Acta 432, 157 (2001). 